\title{
VALIDATION OF A FRACTIONAL MODEL FOR ERYTHROCYTE SEDIMENTATION RATE
}

\author{
J. VANTERLER DA C. SOUSA ${ }^{1}$, MAGUN N. N. DOS SANTOS, L. A. MAGNA, \\ AND E. CAPELAS DE OLIVEIRA ${ }^{1}$
}

\begin{abstract}
We present the validation of a recent fractional mathematical model for erythrocyte sedimentation proposed by Sharma et al. [13. The model uses a Caputo fractional derivative to build a time fractional diffusion equation suitable to predict blood sedimentation rates. This validation was carried out by means of erythrocyte sedimentation tests in laboratory. Data on sedimentation rates (percentages) were analyzed and compared with the analytical solution of the time fractional diffusion equation. The behavior of the analytical solution related to each blood sample sedimentation data was described and analyzed.

Keywords: Clinical laboratory tests, Erythrocyte sedimentation rate, Fractional Calculus, Time-fractional diffusion equation.

MSC 2010 subject classifications. 26A06; 26A33; 33RXX;34A30;35KXX;92BXX;92DXX.
\end{abstract}

\section{IntroduCtion}

The study of differential equations with integer order has always proved important and useful in mathematics, in particular, for the formulation of mathematical models [1, 2, 3, 4, 5]. Several such models are based on ordinary or partial differential equations. However, for systems with many variables it is usually very difficult to build models that match reality.

Modeling such complex systems by means of a differential equation of non-integer order presents some advantages as compared with mathematical models that use only classical, integer order operators. Indeed, it has been realized that the use of differential equations of fractional order to model certain complex phenomena usually provides better descriptions of their behavior, allowing us to obtain more accurate information about the underlying physical systems [6, 7, 8, 9, 10, 11]. Thus, fractional calculus became popular because of its importance and relevance, specifically, due to its numerous applications in several fields of science and particularly in biology and medicine, in which the authors Sousa et al. [12], using the Caputo fractional derivative, introduced a fractional mathematical model that describes the concentration of nutrients in blood, a parameter that affects Erythrocyte Sedimentation Rate (ESR) and which contain, as a particular case, the result obtained in [13]. 
Due to this popularity of fractional calculus, there are numerous recent works related to biology and medicine [14, 15, 16, 17, 18. The motivation for this work came from a mathematical model proposed by Sharma et al. [13]. First, Sousa et al. [12], using the Caputo fractional derivative, proposed a fractional version of the model by Sharma et al. [13], in order to generalize it and, possibly, make it more accurate. In order to obtain more accurate model information with respect to reality, the model must be tested and verified, that is, by ESR test, look at the data and compare with the analytical solution of the time fractional diffusion equation.

The paper is organized as follows: In section 2, we present a brief explanation about ESR, together with some tables showing analytical and clinical factors that affect erythrocyte sedimentation, increasing and decreasing ESR. A brief description of the erythrocyte sedimentation process and its three phases, rouleaux formation, precipitation and packaging closes the section. In section 3, we present our fractional mathematical model and the corresponding initial and boundary conditions. The analytical solution of the fractional model is presented and the solution of the mathematical model proposed by Sharma et al. [13] is recovered. In section 4 we present the experiments conducted in order to obtain experimental values (percentages) of ESR for 8 blood samples from 8 different individuals, which would be compared with the fractional mathematical model. The results are presented in two complete tables. In section 5, the main result of this paper, we validate the fractional mathematical model using data from the erythrocyte sedimentation tests of the 8 samples. We present some graphs and discuss the results obtained. Concluding remarks close the paper.

\section{Erythrocyte Sedimentation Rate}

ESR is a classic clinical test that measures how far erythrocytes settle into the bottom of a test tube over a 1 hour period. The test was originally described in 1897 by Biernacki in Poland [35, 36, 37, 38]. It was introduced by Fahraeus and Westergren at the beginning of the nineteenth century [19, 20, 21, 22].

ESR is in fact a very imprecise test due to the influence of analytical factors such as temperature, table slope and stability, and clinical factors like anemia, giant cells, diabetes, AIDS, smoking, drinking, weight and even height, which can give rise to false-positive and false-negative results [23, 24, 25].

Among clinical factors, the erythrocytes themselves and influence of plasma proteins, associated with inflammation are the ones that most influence ESR test results [26, 27]. Nevertheless, the role of ESR in clinical decision making under non-characteristic conditions has been reestablished in different settings, including rheumatology, hematology and even orthopedics [28, 29, 30, 31, 32, 33, 34.

The erythrocyte sedimentation test for red blood cells is performed within a vertical 200 mm blood test tube. The following two tables present the clinical factors that increase and 
decrease ESR. For the preparation of Table 1 we used the papers [39, 40, 41, 42, 43, 44, 45, 46, 47, 48, 49, 50, 51, 52.

Table 1 - Factors influencing Erythrocyte Sedimentation.

\begin{tabular}{|c|c|}
\hline ESR increases & ESR decreases \\
\hline Pregnancy & Polycythemia \\
\hline Old age & Dysfibrinogenemia and afibrinogenemia \\
\hline Anemia & Intravascular Diffuse Coagulation \\
\hline $\begin{array}{c}\text { High concentration of } \\
\text { non-fibrogenic proteins }\end{array}$ & Congestive heart failure \\
\hline Renal Insufficiency & Valproic Acid \\
\hline Heparin & Cachexia \\
\hline Rheumatoid Arthritis & Hereditary Spherocytosis \\
\hline Tuberculosis & Hyperglycemia \\
\hline Acute Infections & Acanthocytosis \\
\hline Kidney Disease & Microcytosis \\
\hline Macrocytosis & Spherocytosis \\
\hline Dextran & Thalassemia \\
\hline Diabetes Mellitus & Cortisone \\
\hline Gout & Quinine \\
\hline Multiple Myeloma & \\
\hline Myocardial Infarction & \\
\hline Rheumatic Fever & \\
\hline Syphilis & \\
\hline Temporal Arteritis & \\
\hline
\end{tabular}

On the other hand, it is important to have in mind that ESR values are different for men, women, children and elderly people. Table 2 presents the reference values of ESR for each type of individual. For the preparation of Table 2 we used references [53, 54, 55, 56, 57].

Table 2 - Normal values of ESR

\begin{tabular}{|c|c|c|}
\hline Author & Patient & Values in $\mathrm{mm}$ \\
\hline & Children & $4-7$ \\
\hline Miller & Men & $3-5$ \\
\hline & Women & $4-7$ \\
\hline & & \\
\hline & Children & $0-10$ \\
\hline Borges & Man & $0-15$ \\
\hline & Women & $0-20$ \\
\hline
\end{tabular}


Erythrocytes usually form aggregates, called rouleaux, which resemble piles of coins. However, the formation of rouleaux does not occur in the blood flow of a healthy human.

The erythrocyte sedimentation process can be divided in three phases: rouleaux formation, precipitation and packaging. Rouleaux formation is the most influential phase in determining the test result. Normally, red blood cells have negative charges on their surfaces and repel each other, while many plasma proteins have positive charges and neutralize the surface charges of erythrocytes, promoting aggregation. Thus, an increase in plasma proteins will be associated with higher ESR. Precipitation is the second phase of the erythrocyte sedimentation process; it occurs over a period of 40 min. Aggregates of erythrocytes fall under the influence of gravity at a constant rate. Large aggregates fall faster than small aggregates and isolated cells. The falling aggregates induce an upward plasma current that delays sedimentation. Finally, the packaging stage takes place during $10 \mathrm{~min}$. The sedimentation rate decreases and cells begin to pack at the bottom of the tube. In this way, the erythrocyte sedimentation process is terminated [60, 61].

\section{Fractional mathematical model}

In this section we describe, as a review, the fractional mathematical model by means of the Caputo fractional derivative and the corresponding analytical solution proposed by Sharma et al. [12].

The concentration of nutrients in blood is a function $C(x, t)$ twice continuously differentiable that satisfies the following non-homogeneous time-fractional partial differential equation (PDE),

$$
D_{L} \mathcal{D}_{x}^{2} C(x, t)-\mathcal{D}_{t}^{\mu} C(x, t)=\phi(x, t),
$$

where $\mathcal{D}_{t}^{\mu} \equiv \frac{\partial^{\mu}}{\partial t^{\mu}}$ is the Caputo fractional derivative, with $0<\mu \leq 1, D_{L}$ is a positive constant and $\phi(x, t)$ is a function twice continuously differentiable describing the nutrient transfer rate and which satisfies the PDE

$$
D \mathcal{D}_{x}^{2} \phi(x, t)-k \phi(x, t)-\mathcal{D}_{t} \phi(x, t)=0,
$$

with $D$ and $k$ both positive constants.

The initial and boundary conditions imposed here are given by

$$
\begin{cases}\phi(x, 0)=\exp \left(-\sqrt{\frac{k-a}{D}} x\right), & k \geq a, D>0 \\ \phi(0, t)=\exp (-a t), & t>0 \\ \phi(\infty, t)=0, & t>0 .\end{cases}
$$

The solutions of the Eq.(3.2) can be written as

$$
\phi(x, t)=\exp (-(a t+b x))
$$


where $b^{2}=\frac{(k-a)}{D}>0$ and $a$ is a constant to be adequately chosen from a known value of $\phi(x, t)$.

Furthermore, we must impose the initial and boundary conditions for Eq.(3.1):

$$
\begin{cases}C(x, 0)=0, & x \geq 0 \\ C(0, t)=1, & t>0 \\ C(\infty, t)=0, & t>0\end{cases}
$$

with $C(x, t) \in C^{2}[0, b]$.

Thus, from these considerations, it follows that the time-fractional mathematical model to be addressed is composed of a non-homogeneous fractional PDE

$$
D_{L} \mathcal{D}_{x}^{2} C(x, t)-\mathcal{D}_{t}^{\mu} C(x, t)=\exp (-(a t+b x)), \quad a, b \in \mathbb{R},
$$

with initial and boundary conditions given by Eq. (3.3. and $0<\mu \leq 1$

We solve this problem, employing the methodology of Laplace transform to convert the nonhomogeneous fractional PDE into a non-homogeneous linear ordinary differential equation.

Thus, the solution associated with our problem, i.e., a solution of Eq.(3.4) satisfying the conditions given by Eq.(3.3), is [12]

$$
\begin{aligned}
C(x, t)= & t^{\mu} \sum_{m=0}^{\infty} \frac{\left(-\alpha x t^{-\mu / 2}\right)^{m}}{m !} \sum_{k=0}^{\infty}(-a t)^{k} \mathbb{E}_{\mu, \mu+k+1-\mu m / 2}\left(\beta^{2} t^{\mu}\right)+ \\
& +\mathbb{W}\left(-\mu / 2,1 ;-\frac{\alpha x}{t^{\mu / 2}}\right)-\exp (-b x) t^{\mu} \sum_{k=0}^{\infty}(-a t)^{k} \mathbb{E}_{\mu, \mu+k+1}\left(\beta^{2} t^{\mu}\right),
\end{aligned}
$$

where $\mathbb{E}_{\mu, \gamma}(\cdot)$ is the two-parameter Mittag-Leffler function, $\mathbb{W}(a, b ; \cdot)$ is the Wright function [62], and the parameters are given by $\alpha^{2}=1 / D_{L}, \beta^{2}=b^{2} D_{L}$ and $0<\mu \leq 1$. The solution given by Eq.(3.5) is $A C^{n}[0, b]$ and class $C^{2}$, then substituting it in Eq.(3.4) and evaluating the calculation we verify that it satisfies the initial value problem [63].

Note that, the solution of the fractional PDE in the limit $\mu \rightarrow 1$, recover the result by Sharma et al. [13].

\section{EXPERIMENTAL}

4.1. Materials and methods. The ESR tests were conducted at the Hematology Laboratory of the Clinical Hospital, State University of Campinas, state of São Paulo, southeast Brazil, during the period of August 14-15, 2017, all of them between 2:30 pm and 4:00 pm. For the erythrocyte sedimentation test, the Westergren [19, 20, 21, 22] method was adopted as the reference method for ESR measurement by the international council of ICSH [64, 65]. On this date, 8 samples were collected, 4 males and 4 females. We used a test tube of length 
$200 \mathrm{~mm}$, but for evaluation purposes, we consider up to $120 \mathrm{~mm}$ height with an ambient temperature of $22^{\mathrm{O}} \mathrm{C}$ and the angle between the tube and the table is $90^{\mathrm{O}}$.

Patient blood samples were placed in test tubes containing no anticoagulant in the 8 samples. The height of the erythrocyte column in the test tube, in millimeters, was recorded at a 5 min interval for 1 hour, and was subsequently converted to sedimentation rate (percentage) according to the decreased proportion in height. The following tables indicate the values of ESR and clinical factors of the tests carried out on the 8 samples collected. Table 3, below, describes the sedimentation rate of each individual as time progresses. A detailed description of some information from the individuals in whom erythrocyte sedimentation tests were performed are shown in Table 4. An important observation related to Table 4 is the fact that besides presenting the ESR values (manual sedimentation), we also present the sedimentation performed in the automated system.

The reason for presenting these two versions, made manually and by device, is that the version via apparatus changes the properties of the blood and consequently the sedimentation. In this sense, it is necessary and important to present the difference between the two corresponding rates. 
Table 3 - Sedimentation values in the time intervals.

\begin{tabular}{|c|c|c|c|c|c|c|c|c|c|c|c|c|c|c|}
\hline Time/Pipe & 0 & 5 & 10 & 15 & 20 & 25 & 30 & 35 & 40 & 45 & 50 & 55 & 60 & \\
\hline Pipe 1 - F & 0 & 0.83 & 0.83 & 0.83 & 1.66 & 3.32 & 6.64 & 9.96 & 13.28 & 16.60 & 19.09 & 24.07 & 25.73 & \\
\hline Pipe 2 - F & 0 & 0.83 & 0.83 & 0.83 & 1.66 & 2.49 & 3.32 & 4.15 & 5.81 & 7.47 & 9.96 & 11.62 & 14.11 & \\
\hline Pipe 3 - F & 0 & 0.83 & 0.83 & 0.83 & 2.49 & 4.98 & 9.96 & 14.11 & 20.75 & 29.05 & 34.86 & 40.67 & 45.65 & $\mathrm{E}$ \\
\hline Pipe 4 - F & 0 & 1.66 & 1.66 & 2.49 & 3.32 & 3.32 & 8.30 & 19.09 & 30.71 & 41.50 & 51.46 & 59.76 & 65.57 & $\mathrm{~S}$ \\
\hline Pipe 1 - M & 0 & 0 & 0.83 & 0.83 & 1.66 & 1.66 & 2.49 & 2.49 & 4.15 & 5.81 & 7.47 & 9.96 & 12.45 & $\mathrm{R}$ \\
\hline Pipe 2 - M & 0 & 0 & 0.83 & 0.83 & 0.83 & 0.83 & 1.66 & 1.66 & 2.49 & 3.32 & 4.98 & 5.91 & 6.64 & \\
\hline Pipe 3 - M & 0 & 0.83 & 1.66 & 2.49 & 4.15 & 7.47 & 12.45 & 18.26 & 23.24 & 29.88 & 35.69 & 40.67 & 45.65 & \\
\hline Pipe 4 - M & 0 & 0 & 0 & 0 & 0.83 & 0.83 & 0.83 & 0.83 & 0.83 & 1.66 & 1.66 & 1.66 & 2.49 & \\
\hline
\end{tabular}


Table 4 - Patient information.

\begin{tabular}{|c|c|c|c|c|c|c|c|c|}
\hline Label & Sex & Height & Weight & BMI & Man. Sed. & Apa. Sed. & Disorder & Diff. \\
\hline 1 & F & $1.60 \mathrm{~m}$ & $72.00 \mathrm{~kg}$ & 28.1 & $24.73 \%$ & $27.00 \%$ & Bursitis Trochanterica & $9.18 \%$ \\
\hline 2 & $\mathrm{~F}$ & $1.58 \mathrm{~m}$ & $65.00 \mathrm{~kg}$ & 26.0 & $14.11 \%$ & $33.00 \%$ & Spondylarthritis & $133.88 \%$ \\
\hline 3 & $\mathrm{~F}$ & $1.52 \mathrm{~m}$ & $42.70 \mathrm{~kg}$ & 18.5 & $45.65 \%$ & $50.00 \%$ & Control & $9.53 \%$ \\
\hline 4 & $\mathrm{~F}$ & $1.58 \mathrm{~m}$ & $81.00 \mathrm{~kg}$ & 32.4 & $65.57 \%$ & $68.00 \%$ & Polyarthralgia & $3.71 \%$ \\
\hline 5 & $\mathrm{M}$ & $1.67 \mathrm{~m}$ & $78.50 \mathrm{~kg}$ & 28.1 & $12.45 \%$ & $19.00 \%$ & Rheumatoid arthritis & $52.61 \%$ \\
\hline 6 & $\mathrm{M}$ & $1.90 \mathrm{~m}$ & $105.0 \mathrm{~kg}$ & 29.1 & $6.64 \%$ & $3.00 \%$ & Lupus & $-54.82 \%$ \\
\hline 7 & $\mathrm{M}$ & $1.69 \mathrm{~m}$ & $74.00 \mathrm{~kg}$ & 25.9 & $45.65 \%$ & $39.00 \%$ & Retinopathy & $-14.57 \%$ \\
\hline 8 & $\mathrm{M}$ & $1.87 \mathrm{~m}$ & $73.00 \mathrm{~kg}$ & 20.9 & $2.49 \%$ & $3.00 \%$ & $\frac{\text { Lupus Erythematosus }}{2}$ & \multirow{2}{*}{$20.48 \%$} \\
\hline
\end{tabular}




\section{Remark 1.}

- For individuals 1, 2 and 3: unlikely to influence ESR;

- For individuals 4 and \%: may influence ESR;

- For individuals 5, 6 and 8: do influence ESR.

\section{Results And Discussion}

In this section, we will present the graphs of the results obtained in the ESR realization and make some analysis and comparisons with the solution of the fractional diffusion equation Eq.(3.1). Discussions involving the sedimentation rate of erythrocytes, the data collected and the solution of the fractional diffusion equation, conclude the section.

We start with the analysis of Graphs 1-4, which represent the sedimentation rate of four males.

Figure 1. ESR person 1: Male.

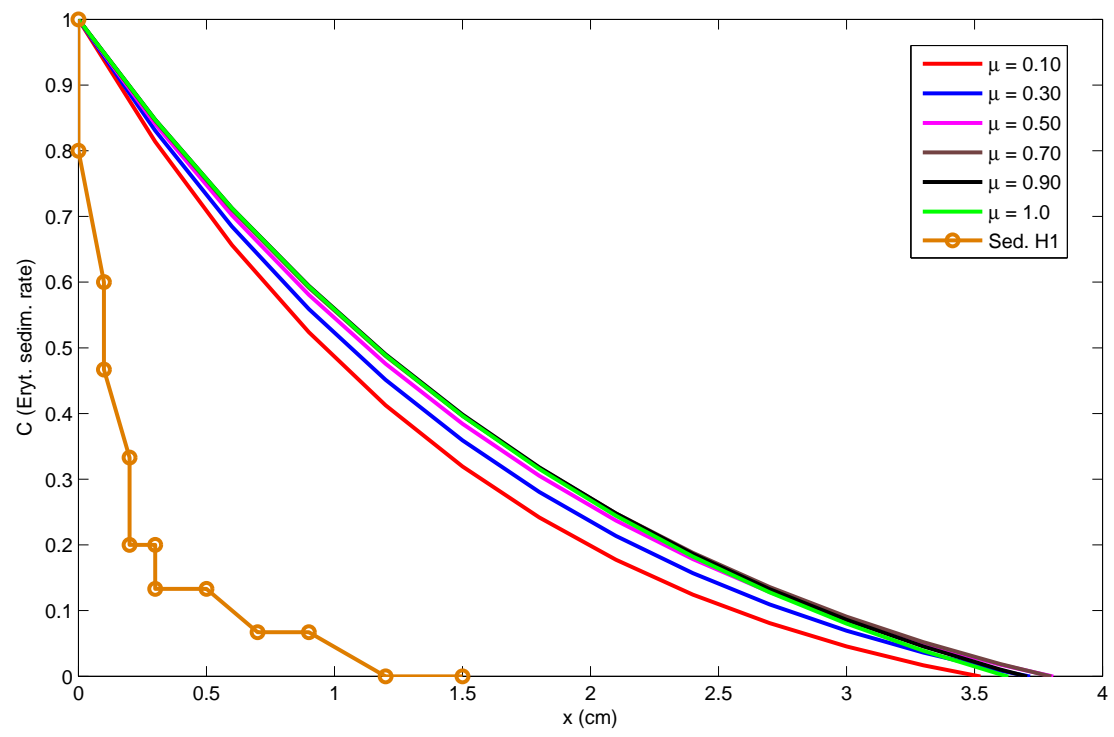


FiguRE 2. ESR person 2: Male.

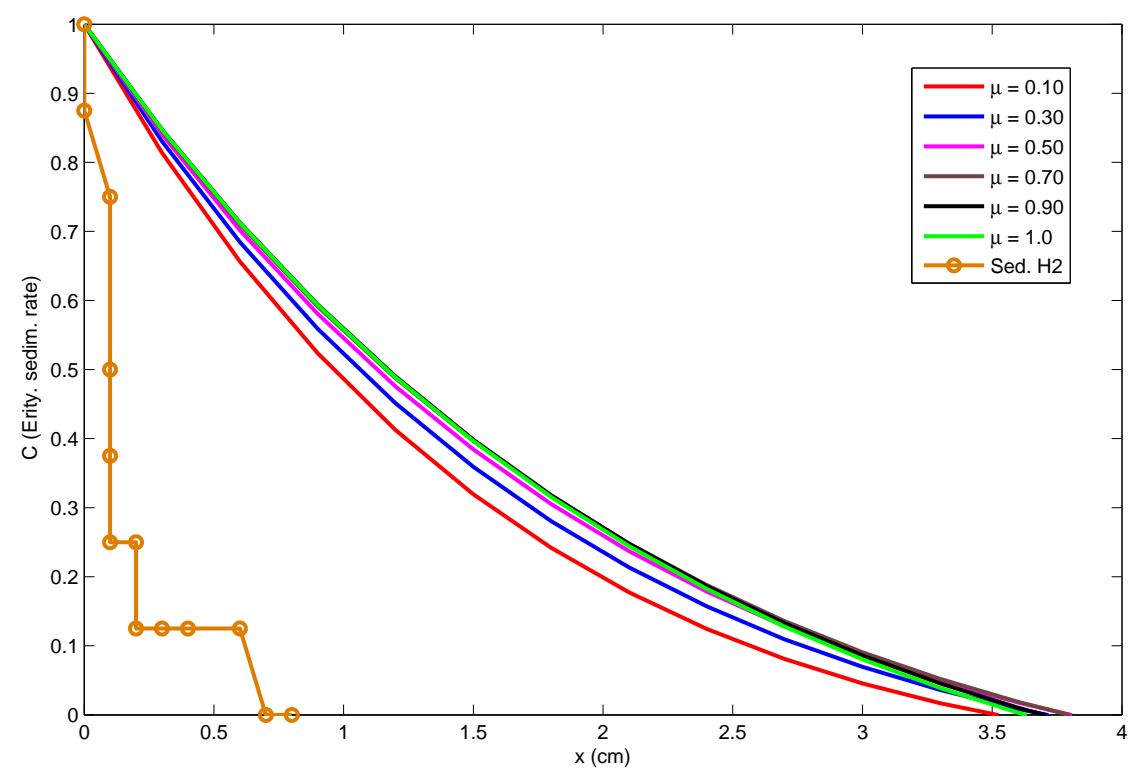

FiguRE 3. ESR person 3: Male.

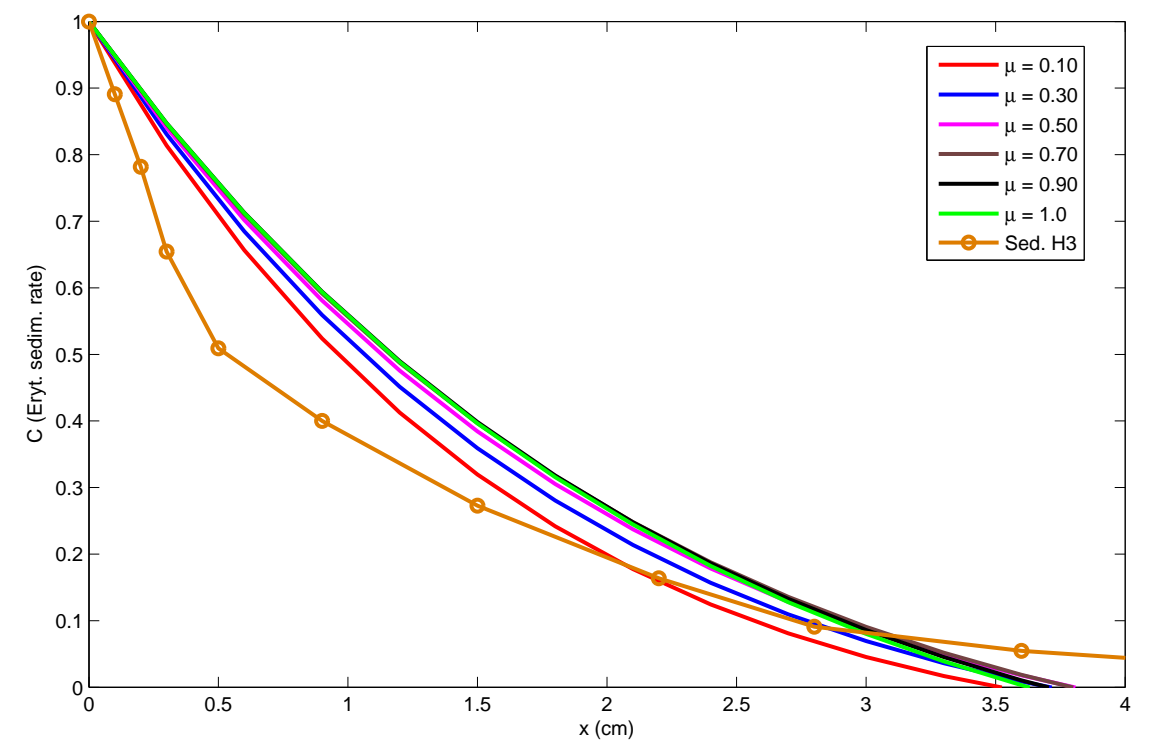


FiguRE 4. ESR person 4: Male.

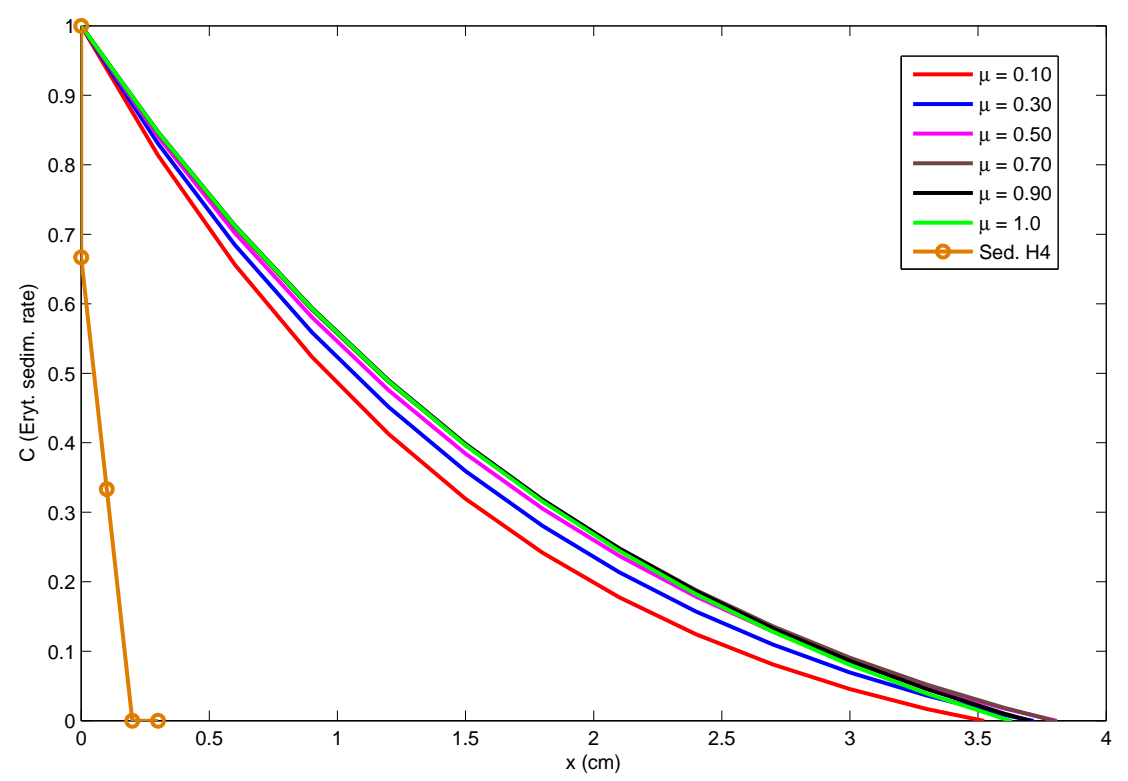

With the purpose to look at the data of individuals, and plot their respective graphs, for a particular choice of the parameter $0<\mu \leq 1$, we tried to approach the analytic solution of the fractional diffusion equation and obtain more precise information on erythrocyte sedimentation behavior in that interval. Then, Graphs 1-4, allow to carry out an analysis of the sedimentation of erythrocytes. The graphs were plotted using the software MALTAB 6.10.

In order to look at the data and validate the fractional mathematical model, recently introduced by Sousa et al. [12], the graphs present an expected behavior, in the sense that each individual has a certain clinical problem. The erythrocyte sedimentation behavior via a graphical analysis varies from individual to individual. Note that from the graph of male 1, the erythrocyte sedimentation behavior presents a characteristic similar to the solution of the fractional diffusion equation, that is, as it moves away from the border $(x \neq 0)$, the concentration of nutrients decreases. On the other hand, the graphs of individuals 2 and 4, the characteristic of the sedimentation curve does not present a good behavior, this is due to the characteristics of each individual, from clinical factors among them, the age. However, if we perform other experiments, we could obtain better results and consequently the behavior of the ESR graph is somehow best viewed by the analytical solution given by Eq. (3.5). On the other hand, it is possible to note that the behavior of the analytical solution of Eq.(3.5) better approach the erythrocyte sedimentation of individual. In fact, it is possible to choose 
$n$ individuals and to study the graph that describes the ESR and thus to make the model more accurate.

The next Graphs 5-8, refer to the behavior of erythrocytes sedimentation for the other 4 individuals, in this case females.

Figure 5. ESR person 1: Female.

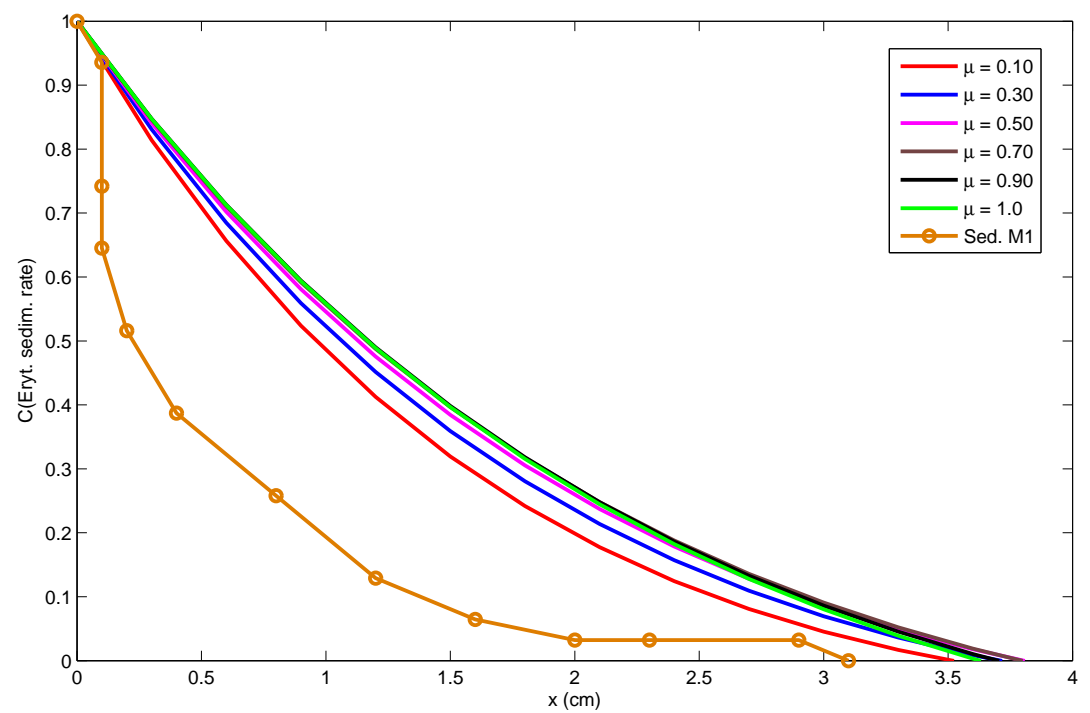

FiguRE 6. ESR person 2: Female

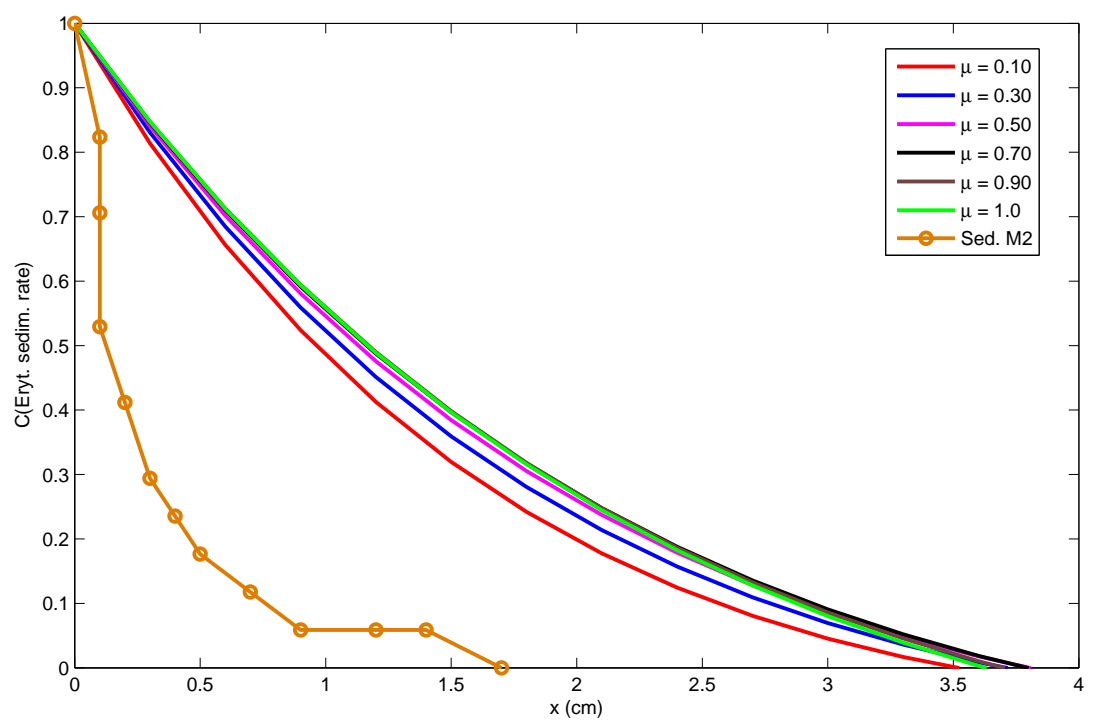


Figure 7. ESR person 3: Female

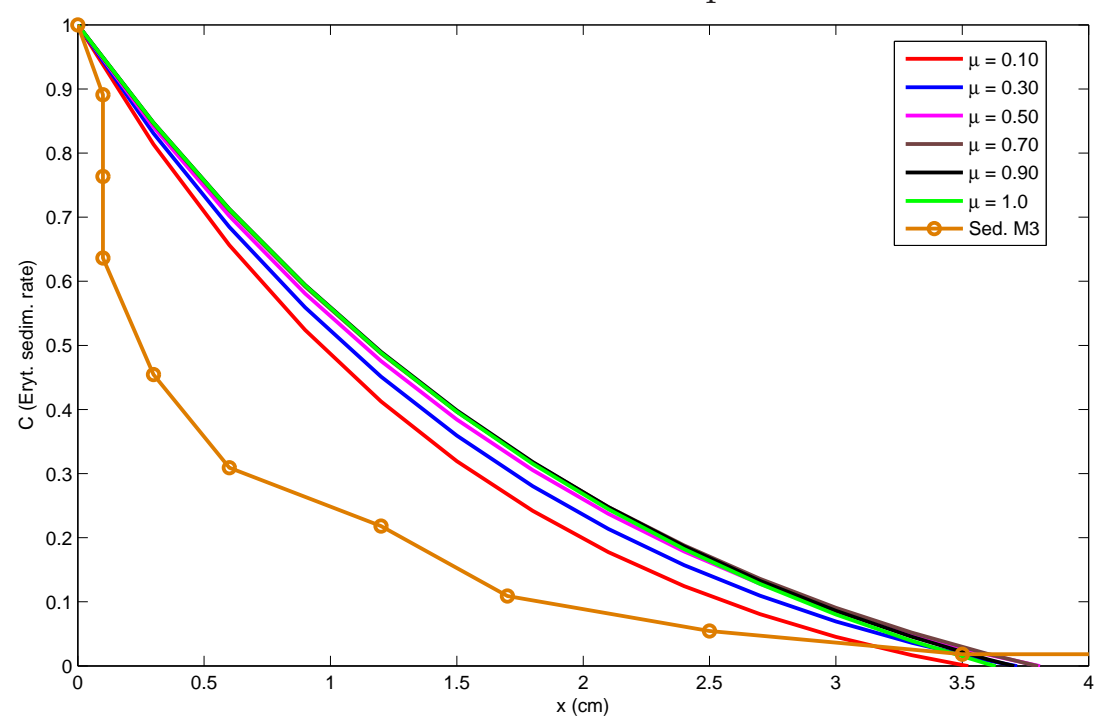

FiguRE 8. ESR person 4: Female

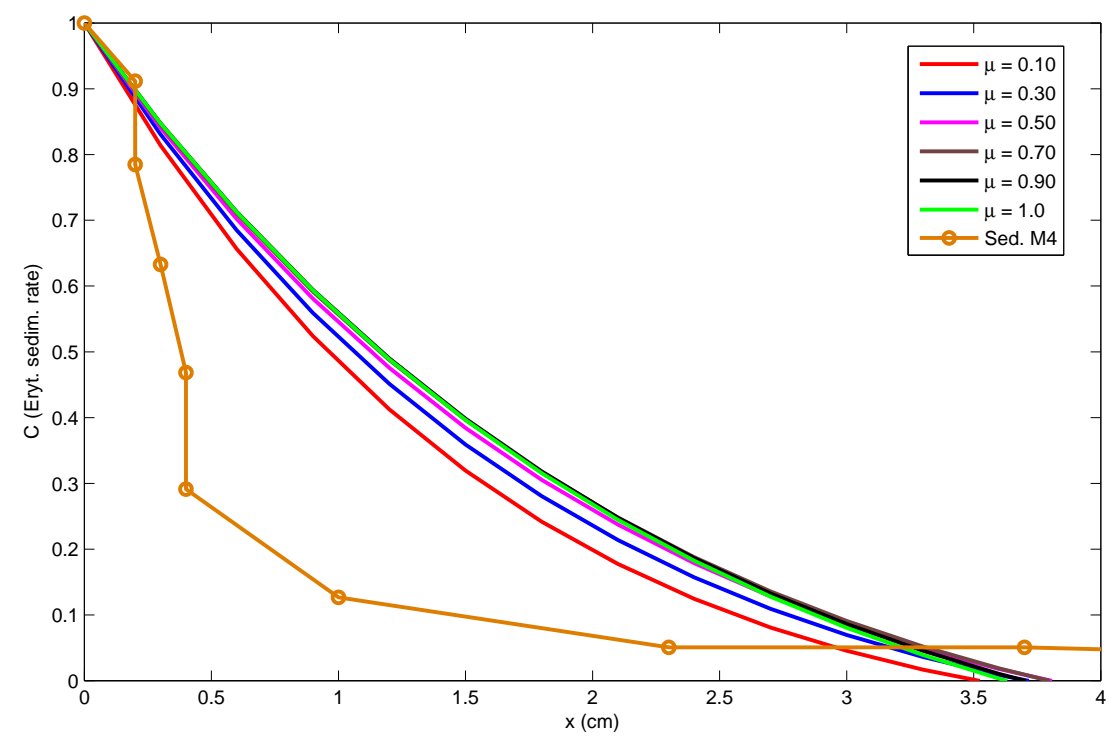

At first, it can be noted that the behavior of ESR of four female individuals presented in the four graphs above is in fact better and the solution of the fractional diffusion equation, the data tape better. However, in the same way that we can perform $n$ tests of female individuals and find others in which the solution Eq.(3.5) tape the data more efficiently, making the fractional mathematical model able to offer information closer to reality in regards to erythrocyte sedimentation. 
In addition, it is worth noting that, as observed in the Graphs 1-8 the fractional mathematical model proposed by Sousa et al. [12] via a Caputo fractional derivative, allows a variation in the order of the derivative, and consequently in the analytical solution of the Eq.(3.1), making it possible to look better at the data. On the other hand, the mathematical model as proposed by Sharma et al. [13] does not allow this freedom to look at the data in the same way as our model. Thus, our fractional mathematical model allows a better reading of the data, that is, the concentration of nutrients in the blood, in relation to the model proposed by Sharma et al. [13.

\section{Concluding Remarks}

After a brief introduction to a fractional mathematical model used to describe the blood concentration of nutrients that influence the sedimentation rate of blood cells, we present the results of laboratory ESR tests with 8 samples, 4 males and 4 females, used to validate that mathematical model. For this sake, the results of sedimentation tests were compared, through graphical analysis, with the analytical solution of the mathematical model. Only 8 samples were enough to carry out this comparison and discuss the model. However, more tests, providing new data, would surely allow a better comprehension of the fractional mathematical model, making it more appropriate to describe reality.

A remarkable advantage of the fractional mathematical model is the freedom to choose the order of the derivative in it and, consequently, the analytical solution of the problem.

With the freedom given to parameter $0<\alpha \leq 1$, we were able to analyze the concentration of nutrients on certain intervals and regions in which the mathematical model proposed by Sharma et al. [13] cannot be used. Our model can thus provide information on the blood concentration of nutrients closer to reality.

In a future work, we intend to consider another type of fractional derivative [66, 67, 69, 68, namely, a general problem of fractional space diffusion. After that we shall carry out the same sedimentation tests and shall use their results to analyze the capabilities of that new model for describing real living systems.

\section{ACKNOWLEDGMENT}

We would like to thank the Dr. J. Emlio Maiorino for several suggestions and comments that helped improve the paper.

\section{REFERENCES}

[1] B. K. Mishra, D. Saini, Mathematical models on computer viruses, Appl. Math. and Comput. 187 (2) (2007) 929-936. 
[2] V. G. Vaidya, F. J. Alexandro, Evaluation of some mathematical models for tumor growth, Inter. J. Bio. Comput. 13 (1) (1982) 19-35.

[3] J. Chattopadhyay, R. R. Sarkar, A. E. L. Abdllaoui, A delay differential equation model on harmful algal blooms in the presence of toxic substances, Math. Med. and Biol. 19 (2) (2002) 137-161.

[4] S. A. Gourley, Y. Kuang, J. D. Nagy, Dynamics of a delay differential equation model of hepatitis b virus infection, J. Biol. Dyn. 2 (2) (2008) 140-153.

[5] M. Villasana, A. Radunskaya, A delay differential equation model for tumor growth, J. Math. Biol. 47 (3) (2003) 270-294.

[6] F. S. Costa, J. C. A. Soares, A. R. G. Plata, E. Capelas Oliveira, On the fractional Harry Dym equation, Comput. and Appl. Math. (2017) 1-15.

[7] E. K. Lenzi, M. K. Lenzi, L. R. Evangelista, L. C. Malacarne, R. S. Mendes, Solutions for a fractional nonlinear diffusion equation with external force and absorbent term, J. Statistical Mechanics: Theory and Experiment 2009 (02) (2009) P02048.

[8] F. S. Costa, J. A. P. F. Marão, J. C. A. Soares, E. Capelas de Oliveira, Similarity solution to fractional nonlinear space-time diffusion-wave equation, J. Math. Phys. 56 (3) (2015) 033507.

[9] F. S. Costa, M. R. A. Pereira, Travelling waves in space-fractional nonlinear diffusion with linear convection, J. Appl. Math. and Phys. 5 (02) (2017) 462.

[10] E. Capelas de Oliveira, F. Mainardi, J. Vaz, Models based on Mittag-Leffler functions for anomalous relaxation in dielectrics, The European Phys. J. Special Topics 193 (1) (2011) 161-171.

[11] E. Capelas de Oliveira, F. Mainardi, J. Vaz, Fractional models of anomalous relaxation based on the Kilbas and Saigo function, Meccanica 49 (9) (2014) 2049-2060.

[12] J. Vanterler da C. Sousa, E. Capelas de Oliveira, L. A. Magna, Fractional calculus and the ESR test, AIMS Mathematics 2 (4) (2017) 692-705.

[13] G. C. Sharma, M. Jain, R. N. Saral, A mathematical model for concentration of blood affecting erythrocyte sedimentation, Comput. Biol. Med., 26 (1996) 1-7.

[14] N. Varalta, A. V. Gomes, R. F. Camargo, A prelude to the fractional calculus applied to tumor dynamic, TEMA (São Carlos) 15 (2) (2014) 211-221.

[15] Y. Ding, H. Ye, A fractional-order differential equation model of hiv infection of cd4+ t-cells, Math. and Comput. Model. 50 (3) (2009) 386-392.

[16] T. A. M. Langlands, B. I. Henry, S. L. Wearne, Fractional cable equation models for anomalous electrodiffusion in nerve cells: infinite domain solutions, J. Math. Biol. 59 (6) (2009) 761.

[17] C. Tian, Turing pattern formation in a semiarid vegetation model with fractional-in-space diffusion, Bull. Math. Biol. 77 (11) (2015) 2072-2085.

[18] S. M. A. Pahnehkolaei, A. Alfi, J. T. Machado, Dynamic stability analysis of fractional order leaky integrator echo state neural networks, Commun. Nonlinear Sci. Numer. Simulat. 47 (2017) 328-337.

[19] A. Westergren, Studies of the suspension stability of the blood in pulmonary tuberculosis, Acta Medica Scandinavica, Wiley Online Library, 54 (1) (1921) 247-282.

[20] A. Westergren, The technique of the red cell sedimentation reaction, Am. Rev. Tuberc, 14 (1926) 94-101.

[21] R. Fahraeus, The suspension-stability of blood, Acta Med. Scand., 55 (1921) 1-228.

[22] R. Fahraeus, The suspension stability of the blood. Physiological Reviews, Am. Physiological Soc., 9 (2) (1929) 241-274.

[23] N. Van den Broek, E. Letsky, Pregnancy and the erythrocyte sedimentation rate, British J. of Obstetrics and Gynaecology, Elsevier, 108 (11) (2001) 1164-1167.

[24] J. S. Olshaker, D. A. Jerrard, Pregnancy and the erythrocyte sedimentation rate, The J. of Emergency Medicine, Elsevier, 108 (6) (1997) 869-874.

[25] S. E. Bedell, B. T. Bush, Erythrocyte sedimentation rate. From folklore to facts, The American J. of Medicine, Elsevier, 78 (6) (1985) 1001-1009.

[26] I. Talstad, P. Scheie, H. Dalen, J. Roli, Influence of plasma proteins on erythrocyte morphology and sedimentation, Scandinavian J. of Haematology, Wiley Online Library, 31 (5) (1983) 478-484. 
[27] J. Whelan, C. R. Huang, A. L. Copley, Concentration profiles in erythrocyte sedimentation in human whole blood, J. Biorheology, 7 (4) (1971) 205-212.

[28] R. Cheung, D. O. Sillence, M. C. Tchan, Homocysteine and erythrocyte sedimentation rate correlate with cerebrovascular disease in fabry disease, in: JIMD Rep., 2012, pp. 101-105.

[29] Y. Choi, B. Park, K. Kim, B. C. Jeong, S. I. Seo, S. S. Jeon, H. Y. Choi, J. E. Lee, H. M. Lee, Erythrocyte sedimentation rate and anaemia are independent predictors of survival in patients with clear cell renal cell carcinoma, Br. J. Cancer 108 (2) (2013) 387.

[30] N. V. Greidanus, B. A. Masri, D. S. Garbuz, S. D. Wilson, M. G. McAlinden, M. Xu, C. P. Duncan, Use of erythrocyte sedimentation rate and c-reactive protein level to diagnose infection before revision total knee arthroplasty: a prospective evaluation, J. Bone Joint Surg Am. 89 (7) (2007) 1409-1416.

[31] G. Hauser, M. Tkalcic, S. Pletikosic, N. Grabar, D. Stimac, Erythrocyte sedimentation rate-possible role in determining the existence of the low grade inflammation in irritable bowel syndrome patients, Med. Hypotheses 78 (6) (2012) 818-820.

[32] G. Stojan, H. Fang, L. Magder, M. Petri, Erythrocyte sedimentation rate is a predictor of renal and overall sle disease activity, Lupus 22 (8) (2013) 827-834.

[33] A. Tamhane, D. T. Redden, G. McGwin, E. E. Brown, A. O. Westfall, R. J. Reynolds, L. B. Hughes, D. L. Conn, L. F. Callahan, B. L. Jonas, Comparison of the disease activity score using erythrocyte sedimentation rate and c-reactive protein in african americans with rheumatoid arthritis, J. Rheumatol. 40 (11) (2013) 1812-1822.

[34] E. Ghanem, V. Antoci, L. Pulido, A. Joshi, W. Hozack, J. Parvizi, The use of receiver operating characteristics analysis in determining erythrocyte sedimentation rate and c-reactive protein levels in diagnosing periprosthetic infection prior to revision total hip arthroplasty, Int. J. Infect. Dis. 13 (6) (2009) e444-e449.

[35] E. Kucharz, The forgotten contribution of dr. Edmund Faustyn Biernacki (1866-1911) to the discovery of the erythrocyte sedimentation rate, The J. of Laboratory and Clinical Medicine, 112 (2) (1988) $279-280$.

[36] E. J. Kucharz, Edmund Biernacki and erythrocyte sedimentation rate, The J. of Laboratory and Clinical Medicine, 329 (1987) 696.

[37] E. Biernacki, Die spontane blutsedimentirung als eine wissenschaftliche und praktisch-klinische untersuchungsmethode?, DMW-Deutsche Medizinische Wochenschrift, Georg Thieme Verlag, Stuttgart, 23 (48) (1897) 769-772.

[38] E. Biernacki, Samoistna sedymentacja krwi, jako naukowa i praktyczno-kliniczna metoda badania (Spontaneous sedimentation of red blood cells in clinical practice), Gazeta Lekarska, 36 (48) (1897) 962-968.

[39] N. Shusterman, P. L. Kimmel, F. L. Kiechle, S. Williams, G. Morrison, I. Singer, Factors influencing erythrocyte sedimentation in patients with chronic renal failure, Arch. Inter. Med. 145 (10) (1985) $1796-1799$.

[40] N. Shusterman, G. Morrison, I. Singer, P. Kimmel, F. Kiechle, The erythrocyte sedimentation rate and chronic renal failure, Ann. Inter. Med. 105 (5) (1986) 801-801.

[41] D. M. Warner, C. R. P. George, Erythrocyte sedimentation rate and related factors in end-stage renal failure, Nephron 57 (2) (1991) 248-248.

[42] P. S. Pasulka, B. R. Bistrian, G. L. Blackburn, Obesity and erythrocyte sedimentation rates, Ann. Inter. Med. 103 (2) (1985) 304-304.

[43] M. W. Morris, F. R. Davey, Basic examination of blood, Clinical diagnosis and management by laboratory methods 20 (2001) 479-519.

[44] C. S. Grace, R. B. Goldrick, Fibrinolysis and body build: interrelationships between blood fibrinolysis, body composition and parameters of lipid and carbohydrate metabolism, J. Atherosclerosis Res. 8 (4) (1968) 705-719.

[45] R. Fahraeus, The influence of the rouleaux formation of the erythrocytes on the rheology of the blood., Acta Med. Scand. 161 (2) (1958) 151. 
[46] M. A. Shearn, I. Y. Kang, Effect of age and sex on the erythrocyte sedimentation rate., J. Rheumatol. 13 (2) (1986) 297-298.

[47] L. E. Bottiger, C. A. Svedberg, Normal erythrocyte sedimentation rate and age., Br. Med. J. 2 (5544) (1967) 85.

[48] N. P. Zauber, A. G. Zauber, Hematologic data of healthy very old people, JAMA 257 (16) (1987) 2181-2184.

[49] J. H. Jandl, Phystology of red blood cells. In: Jandl JH, ed. Textbook of hematolgy. 2d ed., New York: Little, Brown, 1996.

[50] H. Bunting, Sedimentation rates of sickled and non-sickled cells from patients with sickle cell anemia, Am. J. Med. Sci. 198 (2) (1939) 191-192.

[51] R. Glass, Factitiously low esr with chronic lymphocytic leukemia., N. Engl. J. Med. 285 (16) (1971) 921.

[52] R. M. Hutchinson, C. M. Clay, M. R. Simpson, J. K. Wood, Lowered erythrocyte-sedimentation rate with sodium valproate, Lancet 312 (8103) (1978) 1309.

[53] M. L. Brigden, Clinical utility of the erythrocyte sedimentation rate., Am. Family Physician 60 (5) (1999) 1443-1450.

[54] B. I. Solberg, R. J. Olson, Clinical utility of the erythrocyte sedimentation rate: A case study, Clinical Laboratory Science 27 (2) (2014) 72.

[55] G. B. Collares, P. G. Vidigal, Recomendações para o uso da velocidade de hemossedimentação, Rev. Med. Minas Gerais 14 (1) (2014) 52-57.

[56] M. W. Morris, F. R. Davey, Basic examination of blood. in:henry's clinical diagnosis and management by laboratory methods. 20th ed, Philadelphia, W. B. Saunders (2001) 515-519.

[57] M. A. Hameed, S. Waqas, Physiological basis and clinical utility of erythrocyte sedimentation rate, Cont. Med. Edu. 22 (2) (2006) 214-218.

[58] T. Murata, T. W. Secomb, Effects of shear rate on rouleaux formation in simple shear flow, Biorheology $25(1-2)(1988)$ 113-122.

[59] J. Zhang, P. C. Johnson, A. S. Popel, Red blood cell aggregation and dissociation in shear flows simulated by lattice Boltzmann method, J. Biomechanics 41 (1) (2008) 47-55.

[60] R. Hashemi, A. Majidi, H. Motamed, A. Amini, F. Najari, A. Tabatabaey, Erythrocyte sedimentation rate measurement using as a rapid alternative to the Westergren method, Emergency 3 (2) (2015) 50.

[61] C. H. Cha, C. J. Park, Y. J. Cha, H. K. Kim, D. H. Kim, J. H. Bae, J. S. Jung, S. Jang, H. S. Chi, D. S. Lee, Erythrocyte sedimentation rate measurements by test 1 better reflect inflammation than do those by the Westergren method in patients with malignancy, autoimmune disease, or infection, Am. J. Clin. Pathology 131 (2) (2009) 189-194.

[62] R. Gorenflo, A. A. Kilbas, F. Mainardi, S. Rogosin, Mittag-Leffler Functions, Related Topics and Applications, Springer, Berlin, 2014.

[63] J. Vanterler da C. Sousa, Time-fractional diffusion equation (Erythrocyte sedimentation rate), (in Portuguese) Phd Thesis, Imecc-Unicamp, Campinas, (2018).

[64] International Committee for Standardization in Haematology. Reference method for the erythrocyte sedimentation rate (ESR) test on human blood, British J. of Haematology, 24 (1) (1973) 671-673.

[65] International Committee for Standardization in Haematology, Recommendations for measurement of erythrocyte sedimentation rate, J. of Clinical Pathology, 46 (1993) 198-203.

[66] J. Vanterler da C. Sousa, E. Capelas de Oliveira, On the $\psi$-Hilfer fractional derivative, Commun. Nonlinear Sci. Numer. Simulat. 60 (2018) 72-91.

[67] J. Vanterler da C. Sousa, E. Capelas de Oliveira, On two new operators in fractional calculus and application, Submitted, (2018).

[68] J. Vanterler da C. Sousa, E. Capelas de Oliveira, A new fractional derivative of variable order with non-singular kernel and fractional differential equations, Submitted, (2018).

[69] J. Vanterler da C. Sousa, E. Capelas de Oliveira, Mittag-Leffler Functions and the Truncated $\mathcal{V}$ fractional Derivative, Mediterr. J. Math. 16(6) (2017) 244. 
I8VANTERLER DA C. SOUSA ${ }^{1}$, MAGUN N. N. DOS SANTOS, L. A. MAGNA, AND E. CAPELAS DE OLIVEIRA ${ }^{1}$

${ }^{1}$ Department of Applied Mathematics, Institute of Mathematics, Statistics and Scientific Computation, University of Campinas - UniCAMP, rua Sérgio Buarque de Holanda 651, 13083-859, CAMPINAS SP, BRAZIL

E-MAIL: vanterlermatematico@hotmail.com, capelas@ime.unicamp.br

Department of Clinical Pathology, School of Medical Sciences,, University of Campinas -UNICAMP, 13083-887, CAMPINAS, SP, BRAZIL

E-MAIL: magnun@fcm.unicamp.br

Department of Medical Genetics, School of Medical Sciences,, University of Campinas UNICAMP, 13083-887, CAMPINAS, SP, BRAZIL

E-MAIL: amagna@uol.com.br 